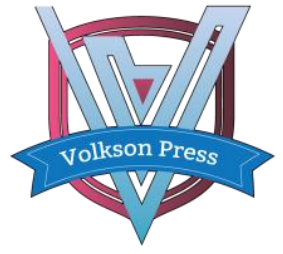

Economics, Finance and Statistics (EFS)

DOI : http://doi.org/10.26480/icefs.01.2018.93.94

\title{
WHERE DOES THE MUSIC SHORT VIDEO INDUSTRY GO TAKE THE EXAMPLE OF VIBRATO APP
}

\author{
Lin Xiaohan \\ Department of North China Electric Power University, No.2 Huilongguan North Agricultural Road, Changping District, Beijing, China. \\ *Corresponding Author Email: 18810912810@163.com
}

This is an open access article distributed under the Creative Commons Attribution License, which permits unrestricted use, distribution, and reproduction in any medium, provided the original work is properly cited.

\section{ARTICLE DETAILS \\ Article History: \\ Received 12 March 2018 \\ Accepted 12 April 2018

\begin{abstract}
In 2016, various types of short video software appeared one after another, and the short video era began. In the first half of 2017, music short videos in the short video vertical industry rose rapidly, and domestic music short video software, such as Vibrato, was formed in China. In the second half of 2017, Vibrato started its internationalization and actively sought overseas growth. This article analyzes the reasons for the shocking explosion and the enlightenment it brings from the aspects of marketing promotion and market demand.
\end{abstract}

Available online 15 May 2018

\section{KEYWORDS}

short video, Vibrato, marketing promotion.

\section{INTRODUCTION}

With the popularization of the Internet, people's demands for social forms have become higher and higher. Not only have they been expressed through text, pictures, and speech, but short videos have integrated multiple expressions [1]. Today, as technology thresholds are getting lower and lower, the short video socialization has become an increasingly popular social networking method favored by netizens.

Vibrato is a music creative short video APP under the headline today. Users select a song at random, create a short video through the body movements and post-editing, and upload it to the vibrato platform to form their own works [2]. The duration is no more than 15 seconds. As nowadays the most popular music creative short video software - Vibrato since its launch, with a variety of music styles, cool visual editing functions, and personalized distribution mechanisms, the young man's desire for expression was successfully opened shortly after coming online and achieved over one billion daily playbacks.

In recent years, music society experienced a single music sharing, text comments, barrage, live broadcast, and the establishment of a community. The audience is bound to expect more diversified musical social forms. In the music short video software with different playing methods, Vibrato takes an important position in a short period of time with a rapid attitude, mainly because its individualized features can better meet the growing media needs of the audience [3]. And this article will analyze the reason and the implications of it from marketing promotion and market demand.

\section{THE CAUSE OF VIBRATO'S RAPIDLY POPULAR EXPLOSION}

\subsection{Precise product positioning}

Vibrato, which can be understood from its name, is a piece of music-related software. The essence of this product is to focus on building young people's music short video community. Different from other platform users such as "Quick Hand", Vibrato is mainly aimed at young people, with $85 \%$ of users under 30 years of age, and the younger age is the biggest feature. As a social software for young music lovers, the function of Vibrato is more exclusive, with simple interface design and low operating threshold; the short video as a whole presents a cool "ghost animal" effect [4]. The shooting of such short video of creative music caters to young people's curiosity and personalized expression needs. Young people are active in thinking, accepting new things quickly, full of curiosity, socially active, and willing to show themselves, both for the Vibrato provides a higher quality of producers, consumers, also provides the rapid spread of the human basis.

\subsection{Personalized features}

Zhang Nan, the general manager of Vibrato, once said: " Vibrato is essentially a short-term video consumer upgrade product." The Vibrato project team had experienced more than 100 kinds of short video products at home and abroad before determining the direction of research, and finally they determined the Vibrato convey "better" research direction. In the era of the popularization of intelligent network today, for most young people, their vision and pursuit of beauty have reached a considerable height. And the beauty of simple external forms has given them a sense of fatigue. With the unique features of personality mini MVs, feature filter props, creative multi-stage mixing and shearing, special effects, video shooting speed adjustment, and launching challenges to the participation of the whole nation, the Vibrato has added personalized services to the products and instilled fresh vitality into the products, enabling users to feel the surprise that " better " brings, in line with people's instinct to pursue beauty, and also get the user's approval.

\subsection{Taking advantage of good publicity opportunities}

In the beginning, the Vibrato's public relations team did not carry out much publicity, but after the users gradually knew the APP and had a certain influence, they started to carry out a small amount of publicity until the public relations team realized that it was only one step away from the explosion, and they started a large area of public relations. The Vibrato public relations team was good at seizing the opportunity to attack at a critical moment, making the chattering "fire" in an instant. At the same time, Vibrato 's public relations platform is mainly concentrated in some large portal websites or vertical technology media, enabling people who are interested in it to quickly know this APP. The chattering public relations team can quickly and effectively spread the product, which made them achieve good results.

\subsection{Effective external communication power}


Despite the fact that the Vibrato is mainly a social platform for sharing content by ordinary users, in the early stage of promotion, Vibrato has successfully captured the audience's attention by relying on Celebrity hype and fan effects. Prior to March 2017, the Baidu index of Vibrato was almost zero. In mid-March, Baidu's index sharply increased due to Yue Yunpeng's forwarding of a microblog that was imitated with a flicker logo. Afterwards, Vibrato also invited a large number of traffic stars to settle in. Relying on celebrity rallying to expand the influence of the platform and content dissemination, it also improved the product's own taste, more in line with the positioning of young people in the first and second tier cities and the psychological needs of users.

Secondly, Vibrato cooperated with today's headlines and Junfen Brothers Media to organize the 2017 National Youth Talent Competition. It can make full use of the offline communication channel and further enhance its influence by spreading the communication site, thus expanding the spread of the communication.

In addition, the expansion of internationalization brings a huge imagination to Vibrato. The rapid development of users in overseas markets is conducive to the future listing. The use of Vibrato to the sea has expanded the space for the development of short video and increased its influence so that the short video can continue to take off for a while. Its overseas deployment strategy also lays the foundation for the domestic application of native products to expand overseas markets and has accumulated valuable experience.

\section{INSPIRATION AND THINKING}

As for the development situation in the short video area, baidu vice President shen shi said that the short video industry as a whole is in its infancy, and it is still far from the point where the pattern has been set. "In terms of the competitive landscape, there is both the competition of the realization model and the competition of traffic distribution, so it can be said that it is a group and it has just started."

In terms of Vibrato, it is a music short video community that focuses on the new generation. Users can share their original short music videos on this platform. Vibrato is a rising star in short video software, as the most outstanding in the short music video software, its market competition strength to be reckoned with, and huge potential for development. It depends on the characteristics and quality of the product itself, external support, and applicable market mechanism strategies. It is well known to more and more people for its extremely fast speed of transmission, and its dissemination trend will also proceed in a more comprehensive direction.

However, the magic of the melody, then cool special effects, and then strange short video, the user will be more tired after watching more, until they are dull, and go away. For this purpose, Vibrato should carefully examine its own deficiencies, plan to increase the "live" function, enrich the product line, enhance the platform's content productivity and appeal, continue to enhance brand competitiveness and market control. In addition, a good platform, brand and product should be continuously interactive with users, listening to users, appreciating users and motivating users, so as to continuously enhance and maintain user stickiness. In the case of Vibrato, its decentralized algorithm and the function of satisfying audience expression requirements can maintain the user's activity well. However, the interaction between users is still relatively simple, and the amount of information conveyed by the output and feedback process is quite different, and social attributes are still weak.

At present, the success of Vibrato can be used for reference by more businesses. However, if Vibrato itself is to escape the short-lived fate, it also needs to add more high-quality and diversified content and strong social functions to maintain user viscosity and activity.

\section{ACKNOWLEDGMENTS}

After more than a month of hard work, I finally completed the writing of the paper. From the beginning of conceiving the thesis title to the completion of the dissertation article, each step is a new attempt and challenge for me. This is also the biggest project that I completed independently during my college education. During this period of time, I learned a lot of knowledge and I have a lot of feelings. From nothing, I started independent learning and experimentation, looked at relevant materials and books, and made my vague concepts gradually clearer to make myself very the tender works are completed step by step. Each improvement is the result of my learning. The success of each experiment will make me excited for a long time. My thesis work is not very mature, there are many shortcomings. But this experience of doing papers has benefited me for life. I feel that doing a thesis is really a matter that I really do with my heart. It is a true process of self-learning and a process of research. Without learning, there can be no research potential. Without my own research, I would not be able to Breakthrough, it is not called the paper. I hope that this experience will enable me to inspire me to continue to progress in my future studies.

\section{REFERENCES}

[1] Xiao, S., Long, X., Shu, Y., Yu, X., Chen, L. 2018. Short-lived video development Another hot spot for the Internet? [N]. People's Posts and Telecommunications, 7, 03-16.

[2] Wudong, Y. 2018.What Revelation of "Vibration" Shakes off [N]. Oriental Tobacco, 2, 03-16

[3] Huiying, L. 2018. Research on the Dependence of Transmitting APPs for Vibrato[J]. China Press, (02), 45-46.

[4] Jiani, W. 2017. Why Music Social Video Software Becomes Popular A Case Study of Vibrato App[J]. New Media Studies, 3 (18), 88-89. 